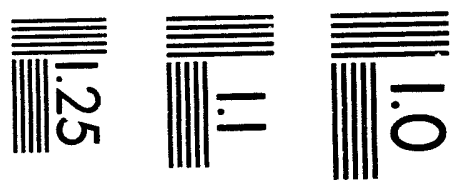

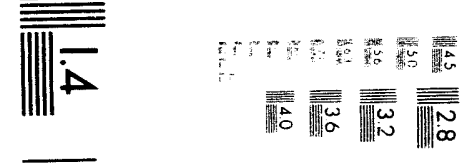

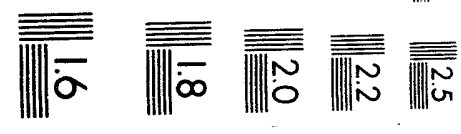



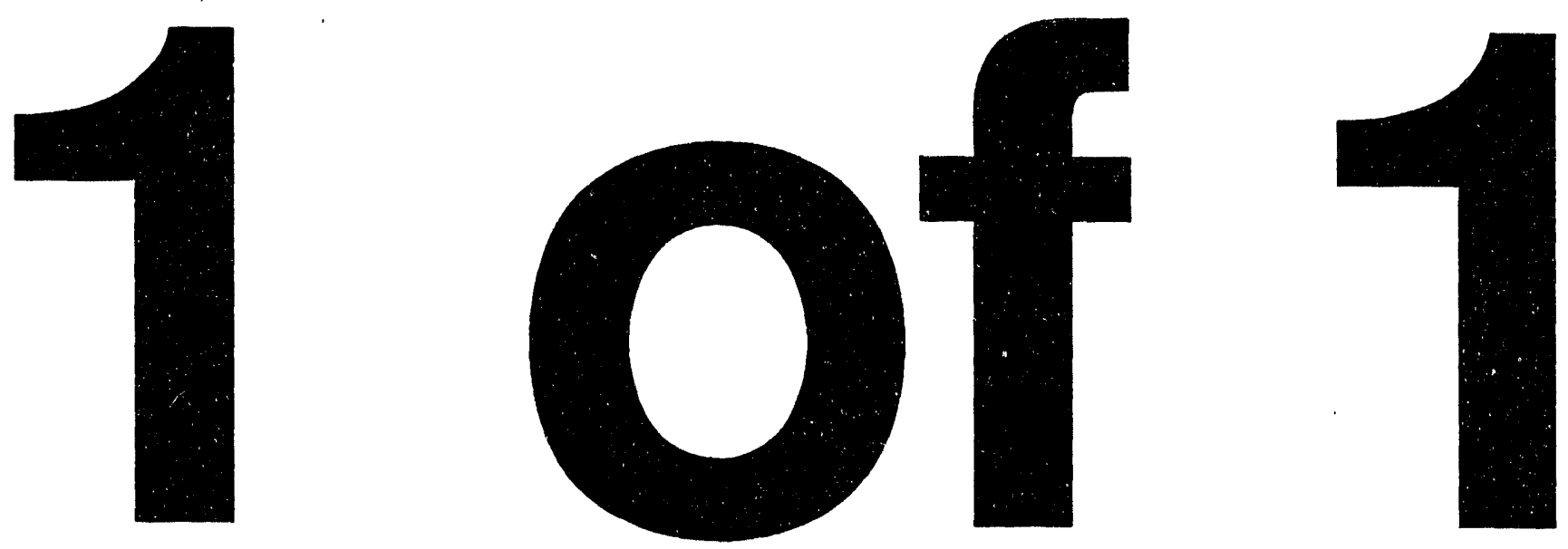


\title{
Investigation of Independence in Inter-Animal Tumor-Type Occurrences within the NTP Rodent-Bioassay Database
}

\author{
Report prepared for the \\ National Research Council, Board on Environmental Studies and Toxicology, \\ Committee on Risk Assessment of Hazardous Air Pollutants
}

by

Kenneth T. Bogen, Dr.P.H.*

Steve Seilkop, Ph.D.**

*Health and Ecological Assessment Division L-453, Lawrence Livermore National Laboratory University of California, 7000 East Avenue, Livermore, CA 94550-9900

Tel: (510) 422-0902, Fax: (510) 422-5748

**Analytical Sciences, Inc., Alston Technical Park, 100 Capitola Drive, Suite 106, Durham, NC 27713, Tel: (919) 544-8500, Fax: (919) 544-7507

May 1, 1993 


\begin{abstract}
Statistically significant elevation in tumor incidence at multiple histologically distinct sites is occasionally observed among rodent bioassays of chemically induced carcinogenesis. If such data are to be relied on (as they have, e.g., by the U.S. EPA) for quantitative cancer potency assessment, their proper analysis requires a knowledge of the extent to which multiple tumor-type occurrences are independent or uncorrelated within individual bioassay animals. Although difficult to assess in a statistically rigorous fashion, a few significant associations among tumor-type occurrences in rodent bioassays have been reported. However, no comprehensive studies of animal-specific tumor-type occurrences at death or sacrifice have been conducted using the extensive set of available NTP rodent-bioassay data, on which most cancer-potency assessment for environmental chemicals is currently based. This report presents the results of such an analysis conducted on behalf of the National Research Council's Committee on Risk Assessment for Hazardous Air Pollutants. Tumor-type associations among individual animals were examined for $\sim 2500$ to 3000 control and $\sim 200$ to 600 treated animals using pathology data from $62 \mathrm{~B} 6 \mathrm{C} 3 \mathrm{~F} 1$ mouse studies and $61 \mathrm{~F} / 344 \mathrm{~N}$ rat studies obtained from a readily available subset of the NTP carcinogenesis bioassay database. No evidence was found for any large correlation in either the onset probability or the prevalence-at-death or sacrifice of any tumor-type pair investigated in control and treated rats and mice, although a few of the small correlations present were statistically significant. Tumor-type occurrences were in most cases nearly independent, and departures from independence, where they did occur, were small. This finding is qualified in that tumor-type onset correlations were measured only indirectly, given the limited nature of the data analyzed.
\end{abstract}




\section{Introduction}

The EPA (1986) cancer-risk guidelines require the default use of a classical multistage model to extrapolate cancer risk based on observed animal bioassay data when adequate epidemiological data are not available for this purpose. The issue of how to use bioassay data that indicate dose-related effects for multiple tumor types is addressed by these guidelines as follows:

To obtain a total estimate of carcinogenic risk, animals with one or more [histologically distinct] tumor sites or types showing significantly elevated tumor incidence should be pooled and used for [risk] extrapolation. The pooled estimates will generally be used in preference to risk estimates based on single types or sites.

However, if the multistage risk-extrapolation model is assumed and if different histologically related sites or types of tumors observed to be significantly elevated above background rates are known to occur in a statistically independent fashion among the individual bioassay animals tested, the EPA-recommended procedure relying on aggregate tumor incidence as input may lead to biased estimates of aggregate potency or risk. Under the independence assumption, pooled tumor-incidence data may exclude information relevant to dose-response extrapolation, in that multiple tumor types observed within a single animal given a high chronic dose might, at very low doses, not be expected to cluster within single animals (Bogen, 1990). For potency estimates based

on classical multistage-type models, this statistical problem is avoided completely if aggregate potency is estimated as the sum of tumor-type-specific potencies (Bogen, 1990). If this approach is used, then aggregate increased risk $P$ of incurring one or more of $n$ significant tumor types given a very low dose $D$ may be estimated by

$$
P \approx 1-\underset{i=1}{\exp \left(-\sum_{i}^{n} q_{i} D\right)} \approx \sum_{i=1}^{n} q_{i} D, \quad \text { for } P \ll 1 .
$$


Of course, the type-specific potencies $q_{i}$ are uncertain quantities estimated from bioassay data, so appropriate Monte-Carlo procedures generally must be used to perform the summation indicated in (1).

This alternative to EPA's procedure for estimating aggregate cancer potency depends on the validity of the independent-action assumption regarding the occurrence of different tumor types in any given group of bioassay animals (conditional on the marginal incidence rates for those tumor types for the entire group). The independent-action assumption is certainly consistent with the biological premise of classical multistage models that spontaneous as well as dose-induced tumors arise primarily from random or induced DNA damage in target cells within different tissues, provided the different animals tested are all approximately equally susceptible to background and dose-related events giving rise to tumors. If significant inter-animal heterogeneity exists, the occurrence of multiple tumor types would be expected to cluster within the more susceptible individuals.

In some of the few studies that have focused on tumor-type associations within individual animals, a few significant associations have been noted, mostly negative associations involving one or two specific tumor types among associated pairs. Significant $(p<0.05)$ age- and treatment-adjusted associations for five of 21 sex-specific pairs from six tumor types investigated were reported by Breslow et al. (1974) for experiments involving over 4000 CF-1 mice exposed to DDT, urethane or nothing: negative associations between lymphomas and each of hepatomas (males), lung adenomas (males and females), and mammary and ovarian tumors (females), and a positive association between lymphomas and bone tumors (males). (Upon adjustment for multiple significance tests (Wright, 1992), the association between lymphomas and mammary tumors observed in that study may not be significant at the 0.05 level.) Breslow et al. (1974) suggested that the negative lymphoma-related associations, except perhaps those involving liver tumors, were all likely to be spurious, "due to the relative 
rapidity with which lymphomas tend to kill their bearers." A significant negative association between lymphomas and liver tumors (but not lung tumors) in 1478 similarly exposed CF-1 mice was later confirmed, even after accounting for the relatively rapid lymphoma lethality by use of serial sacrifice information (Wahrendorf 1983). A significant negative correlation between malignant lymphoma and proliferative hepatocellular lesions at death/sacrifice was also found among 1858 male ICI mice (Young and Gries, 1984). Haseman (1983) also noted this significant negative correlation in raw tumor-incidence data for F344 rats from 25 National Toxicology Program (NTP) bioassays (not analyzed at the level of individual animals).

The most comprehensive study of this type involved an examination of age- and treatment-adjusted associations between (66 possible) pairs of 12 tumor types at death/sacrifice in 3813 gamma-irradiated female BALB/c mice reported 21 significant $(p<0.05)$ positive or negative associations, 10 of which were negative and involved reticular tumors considered to be rapidly lethal and generally also involved other tumors considered to be lethal in the animals studied; most of these 10 associations were considered to be spurious due to the effect of lethality (Storer, 1982). The remaining associations considered significant generally were positive and involved endocrinerelated tumors (Harderian, mammary, adrenal, and pituitary tumors), and none of these involved liver tumors. Aside from associations involving reticular sarcomas, and after appropriate statistical adjustment for multiple tests of significance (Wright, 1992), only three of 55 remaining possible associations reported by Storer (1982) appear to be significant at a 0.05 level, all involving Harderian-gland tumors, which, along with ovary, adrenal and pituitary tumors, were all considered to be nonlethal in the animals studied. A recent study of liver-tumor and reticulum-cell-sarcoma incidence in 1004 gammairradiated female $\mathrm{C} 3 \mathrm{H}$ mice supported a significant negative correlation of these tumor types, even after adjustment for the relative lethality of the reticular tumors using causeof-death information available in that study (Mitchell and Turnbull, 1990). 
In other smaller studies, an assumption of independence in tumor-types at death/sacrifice was shown to be consistent with $\mathrm{ED}_{01}$ data on four different tumor types in 366 control female BALB/c mice and six tumor types elevated in 193 such mice exposed to 2-acetylaminofluorine (Finkelstein and Schoenfeld, 1989), as well as with Hazelton Laboratory data on three different tumor types elevated in a total of 142 male albino rats exposed to dibromochloropropane (Bogen, 1990).

No comprehensive study of animal-specific tumor-type occurrences at death/sacrifice has been conducted using the extensive set of available NTP rodentbioassay data, on which most cancer-potency assessment for environmental chemicals is currently based. This report presents the results of such an analysis conducted on behalf of the National Research Council's Committee on Risk Assessment for Hazardous Air Pollutants.

\section{Data Description}

Tumor-type associations among individual animals were examined for both control and treated animals using pathology data from $62 \mathrm{~B} 6 \mathrm{C} 3 \mathrm{~F} 1$ mouse studies and $61 \mathrm{~F} / 344 \mathrm{~N}$ rat studies obtained from a readily available subset of the NTP carcinogenesis bioassay database. Most studies were 2-year studies, although a few were shorter (e.g., 15 months). Separate analyses were conducted for the four sex/species combinations (male and female mice, male and female rats) corresponding to the compounds and species indicated in Table 1. Analysis was confined to the following common tumor types (occurring at a rate $>5 \%$ ):

Rats: Adrenal gland: medulla pheochromocytomas (benign or malignant)

Thyroid gland: C-cell adenomas or carcinomas

Pituitary gland: carcinomas or adenomas

Mammary gland: fibromas, fibroadenomas, carcinomas, or adenomas

Leukemia:

lymphocytic, monocytic, mononuclear, or undifferentiated. 
Mice: Lung:

Liver:

Lymphoma: alveolar/bronchiolar adenomas or carcinomas

hepatocellular adenomas, hepatocellular carcinomas, and hepatoblastomas

histiocytic, lymphocytic, mixed, NOS, or undifferentiated.

Analyses of correlations between tumor occurrence in treated animals were based on subsets of the control-animal data, comprising studies for which the NTP declared "clear evidence" of an effect at multiple sites and for which pairs of such effects were exhibited in more than one study (resulting in the use of five rat studies and four mouse studies). The treated animal studies involved tumor types that differed from the control-animal studies, namely, adenomas or carcinomas of: liver, Zymbal's gland, clitoral /preputial gland, and skin in rats; and liver, adrenal and Harderian gland in mice. In both controland treated-animal analyses, evidence of associations from individual studies were pooled as described below.

\section{Statistical Methods}

Associations among statistically significantly elevated tumor-types within individual animals may pertain either to tumor onset probabilities or to prevalence at death/sacrifice or to both. It is well known that associations present at deathisacrifice may differ, sometimes substantially, from those relating to tumor onset, and that the former may be heavily influenced by the latter as a result of the time-dependent action of competing risks (Hoel and Walburg, 1972; Breslow et al., 1974; Wahrendorf, 1983; Lagakos and Ryan, 1985). For example, if the onset probabilities of two different tumor types are statistically independent, but in addition both are rapidly lethal, then there is little probability of their joint occurrence within an individual animal and thus their prevalence at death/sacrifice will be negatively correlated. This fact was the basis for concluding probable "spurious" negative correlations involving rapidly lethal tumor types in previous assessments of tumor-type associations in rodents (Breslow et al., 1974; Storer, 1972). 
Unambiguous detection of associations in onsets of different tumor types requires either serial-sacrifice information or animal- and tumor-specific lethality information (Hoel and Walburg, 1972; Wahrendorf, 1983; Lagakos and Ryan, 1985; Mitchell and Turnbull, 1990), neither of which is available for the NTP data analyzed here. Thus, the present analysis was primarily restricted to an assessment of age-adjusted correlations in tumor-types present at death/sacrifice. This approach provides definitive information on onset (as well as terminal prevalence) correlations only if all tumor types are incidental to fatality. However, as described below, a crude assessment of onset-probability correlations was also conducted using information on tumor lethality obtained from the data studied.

Evaluation of the correlations between occurrences between pairs of tumor types in individual animals observed at death/sacrifice was based on age-adjustment of information from $2 \times 2$ contingency tables that were constructed for pairs of tumor occurrences, as in previous similar studies (Breslow et al, 1974; Storer, 1982; Young and Gries, 1984; Finkelstein and Schoenfeld, 1989). Five survival-age strata within each study were used: (1) first 365 days, (2) 366-546 days (1.5 years), (3) 547-644 days ( 1.75 years), (4) 644-terminal sacrifice ( 2 years), (5) terminal sacrifice. Further stratification addressed the inclusion of the highest two dose groups. Thus, the potential number of analytical strata (i.e., $2 \times 2$ tables) was the number of studies times 5 (the number of temporal strata) times 2 (the number of dose levels). The method of Mantel and Haenszel (1959) was used to combine results from stratum-specific contingency tables and to assess two-tailed significance of overall associations between tumor occurrences. Overall correlations are represented as the weighted averages of corresponding stratum-specific measures, using the numbers of animals in the strata as weights. Adjusted p-values accounting for multiple tests of a zero-correlation null hypothesis were obtained for all control and all treated rats and mice using Hommel's modified Bonferroni procedure (Wright, 1992). 
In the absence of serial sacrifice or lethality information, associations between onsets of pairs of tumor types in individual NTP-bioassay animals were evaluated using two crude techniques. First, a separate correlation analysis was undertaken as above, but using only terminal sacrifice data. This approach provides definitive information on onset (as well as terminal prevalence) correlations only if no animals die prior to terminal sacrifice, but may nevertheless provide meaningful information if a sufficiently large fraction of animals survive until sacrifice. The second approach used was the three-bythree contingency-table method for detection of disease-onset associations devised by Mitchell and Turnbull (1990), which requires lethality determinations for each tumor occurrence in each animal. When in doubt regarding such lethality, Mitchell and Turnbull (1990) recommend that it would be prudent to classify a particular occurrence as lethal, because while doing so falsely may reduce the power of the test, the null distribution will not be affected. Thus, the Mitchell-Turnbull test was applied under the assumption that all occurrences of a given tumor type were lethal for all plausibly lethal tumor types. Tumor-type lethality was investigated using Mann-Whitney $U$ statistics comparing survival times of tumor-bearing and tumor-free animals, where all studyspecific results for a given control or treated species and sex were combined to form an overall test by summing these $U$ statistics and dividing this sum by the square root of the sum of the corresponding variances.

\section{Results and Discussion}

The results of our analysis of correlations in incidence at death/sacrifice of tumor types in control rats and mice are summarized in Table 2. These results indicate four significant $\left(\mathrm{p}^{*} \leq 0.05\right)$ but small correlations among 20 sex/tumor-type-pairs investigated in rats (pituitary vs. leukemia in both sexes, and mammary vs. leukemia or pituitary in females-where all those involving leukemia were negative), and no similarly significant correlations among 12 sex/tumor-type-pairs investigated in mice. Corresponding results 
for treated rats and mice are summarized in Table 3. Significant $\left(p^{*} \leq 0.05\right)$ but again generally quite small correlations appear present for two of 12 sex/tumor-type-pairs investigated in treated rats (Zymbal's vs. preputial gland and liver vs. skin tumors in males) and for one of four sex/tumor-type-pairs investigated in treated mice (liver vs. Harderian gland in females), where the liver-related correlations were both positive.

Terminal-sacrifice animals represented 66 to $68 \%$ of all the control mice and 53 to $63 \%$ of all control rats referred to in Table 2. Analysis of tumor-type-prevalence correlations in those animals revealed only a single significant ( $\mathrm{p}^{*} \leq 0.05$ ) correlation, that between mammary and pituitary tumors in female rats $\left(r=0.080, p^{*}=0.013\right)$. Thus, the latter positive (albeit quite small) correlation may pertain to onset as well as prevalence-at-death/sacrifice correlations, whereas the negative leukemia-related correlations noted above for all control rats did not persist in terminal-sacrifice animals. This finding could be explained by relative lethality associated with rodent leukemia/lymphoma, which has been noted in previous studies (Breslow et al., 1974; Wahrendorf, 1983; Young and Gries, 1984; Portier et al., 1986). Terminal-sacrifice animals represented only 14 to $16 \%$ of all the treated rats and 20 to $55 \%$ of ail treated mice referred to in Table 3. Correlation analyses for these treated animals yielded no significant $\left(\mathrm{p}^{*} \leq 0.05\right)$ correlations, which result sheds less light on tumor-onset associations given the greater non-representativeness of these animals.

Our examination of differences in survival time in animals with particular tumors vs. tumor-free animals revealed a few significant differences in control and treated rats. Leukemia in both sexes of control F344 rats studied was associated with a significant reduction in mean survival time $(p<0.001)$. However, this reduction was rather modest: $75 \%$ of leukemia-bearing animals lived until the $23 \mathrm{rd}$ month of the studies and $50 \%$ lived uncil terminal sacrifice. In contrast, $75 \%$ of the leukemia-free animals survived until terminal sacrifice. Thus, any effect of leukemia lethality in inducing negative correlations with other cancers is likely to be small. 
There was also evidence that Zymbal's gland tumors in treated rats resulted in reduced survival times (males, $\mathrm{p}<0.001$; females, $\mathrm{p}=0.003$ ), where the median survival times were reduced by about four months in males (546 vs. 427 days-a reduction more striking than that for leukemia in control males) and by about one month in females. When leukemia and Zymbal's gland tumors in animals dying before terminal sacrifice were assumed to be lethal and all other tumor types incidental, the Mitchell-Turnbull test yielded similar results to those obtained using the unmodified age-stratified analysis. In particular, it provided strong evidence that the small, negative associations betweein leukemia and pituitary-gland tumors in control rats were not due to chance or to differential lethality (males, $p<10^{-9}$; females, $p=0.000057$ ), and it indicated the same regarding the small, negative associations between Zymbal's-gli.ld tumors and preputial/clitoral-gland tumors in treated rats ((males, $\mathrm{p}=0.009$; females, $\mathrm{p}=0.002)$.

In summary, no evidence was found for any large correlation in either the onset probability or the prevalence-at-death/sacrifice of any tumor-type pair investigated in control and treated rats and mice, although a few of the small correlations present were statistically significant. This finding must be qualified to the extent that tumor-type onset correlations were measured indirectly given the limited nature of the data analyzed. Taken together, these findings indicate that tumor-type occurrences in $\mathrm{B} 6 \mathrm{C} 3 \mathrm{~F} 1$ mice and F344 rats used in the NTP bioassays analyzed were in most cases nearly independent, and that departures from independence, where they did occur, were small.

Some of the significantly correlated sites in our analysis of treated animals correspond to site-pairs for which associations between experimental outcomes were recently determined to be statistically significant by Haseman and Lockhart (1992). Our analysis, however, fundamentally differs from theirs in that we examined tumor-typeoccurrence correlations among individual animals in each study considered, while they examined correlations between tumor-type-specific positivity across different studies. For example, Haseman and Lockhart reported a significant relationship $(\mathrm{p}<0.001)$ 
between experimental outcomes of chemicals on the liver and Zymbal's gland in rats. Thus, an experiment in which a significant liver effect occurred was more likely to have an significant effect in Zymbal's gland than those experiments in which there were no effects on the liver. The results of our analysis at the level of individual animals indicates no evidence of this association at this level (Table 3). Thus, the two analyses suggest that the relationship between liver and Zymbal's gland effects reflects similarity between chemicals rather than a predisposition for individual animals to display both of these effects. Unfort'Inately, our analysis was based on only a subset of the studies that Haseman and Lockhart utilized. Future work will extend the results of our study to include all the experiments utilized by Haseman and Lockhart.

\section{Acknowledgements}

We are grateful to the very insightful and helpful comments of Dr. John Bailar in preparing this manuscript.

\section{References}

Bogen, K.T. 1990. Uncertainty in Environmental Health Risk Assessment. Garland Publishing, Inc., New York.

Breslow, N.E., N.E. Day, L. Tomatis, V.S. Turusov, 1974. Associations between tumor types in a large-scale carcinogenesis study. J. Natl. Cancer Inst. 52, 233-239.

Finkelstein, D.M., D.A. Schoenfield. 1989. Analysis of multiple tumor data from a rodent experiment. Biometrics 45, 219-230.

Haseman, J.K. 1983. Patterns of tumor incidence in two-year cancer bioassay feeding studies in Fischer rats. Fundam. Appl. Toxicol. 3, 1-9.

Haseman, J.K., A.M. Lockhart. 1992. Correlations between chemically-related sitespecific carcinogenic effects in long-term studies of rodents. Environ. Health Perspect. (submitted). 
Hoel, D.G., H.E. Walburg, Jr. 1972. Statistical analysis of survival experiments. J. Natl. Cancer Inst. 49, 361-372.

Lagakos, S.W., L.M. Ryan. 1985. Statistical analysis of disease onset and lifetime data from tumorigenicity experiments. Environ. Health Perspect. 63, 211-216.

Mantel, N., W. Haenszel. 1959. Statistical aspects of the analysis of data from retrospective studies of disease. J. Natl. Cancer Inst. 22, 719-748.

Mitchell, T.J., B.W. Turnbull. 1990. Detection of associations between diseases in animal carcinogenicity experiments. Biometrics 46, 359-374.

Portier, C.J., J.C. Hedges, D.G. Hoel. Age-specific models of mortality and tumor onset for historical control animals in the National Toxicology Program's carcinogenicity experiments. Cancer Res. 46, 4372-4378.

Storer, J.B. 1982. Associations between tumor types in irradiated BALB/c female mice. Radiation Res. 92, 396-404.

U.S. Environmental Protection Agency (EPA). 1986. Guidelines for carcinogen risk assessment. Federal Register 51(Sept. 24), 33992-34003.

Wahrendorf, J. 1983. Simultaneous analysis of different tumor types in a long-term carcinogenicity study with scheduled sacrifices. J. Natl. Cancer Inst. 70, 915-921.

Wright, S.P. 1992. Adjusted p-values for simultaneous inference. Biometrics 48, 10051013.

Young, S.S., C.L. Gries. 1984. Exploration of the negative correlation between proliferative hepatocellular lesions and lymphoma in rats and mice-establishment and implications. Fund. Appl. Toxicol. 4, 632-640. 


\section{Table 1}

NTP STUDIES FROM WHICH DATA WERE USED

\section{CHEMICAL}

0-CHLOROBENZALMALONONITRILE (CS-2)

1,2,3-TRICHLOROPROPANE

1,3-BUTADIENE (BUTADIENE)

2,4-DIAMINOPHENOL DIHYDROCHLORIDE

2,4-DICHLOROPHENOL

3,3'-DIMETHOXIBENZIDINE DIHYDROCHLORIDE

3,3'-DIMETHYLBENZIDINE DIHYDROCHLORIDE

4,4-DIAMINO-2, 2-STILBENEDISULFONIC ACID

4-HYDROXYACETANILIDE

4-VINYL-1-CYCLOHEXENE DIEPOXIDE

ALLYL GLYCIDYL ETHER

ALPHA-CHLOROACETOPHENONE

BENZALDEHYDE

BENZYL ACETATE

BROMOFORM

C.I. ACID RED 114

C.I. DIRECT BLUE 15

CARVONE

CHLORAMINE

CI PIGMENT RED 23

CI PIGMENT RED 3

COUMARIN

DICHLORVOS

DIHYDROCOUMARIN

DIMETHOXANE

DIPHENYLHYDANTOIN

DL AMPHETAMINE SULFATE

DOWICIDE EC-7 PENTACHLOROPHENOL

EPINEPHRINE HCL

ETHYL CHLORIDE

ETHYLENE GLYCOL

ETHYLENETHIOUREA

FIREMASTER FF-1 POLYBROMINATED BIPHENYL

FURAN

FURFURAL

GAMMA-BUTYROLACTONE

HC YELLOW 4

HEXACHLOROETHANE

HYDROQUINONE
$\operatorname{MICE}^{a}$

$\operatorname{RATS}^{a}$

$\begin{array}{ll} & \mathrm{X} \\ \mathrm{X}^{b} & \mathrm{X} \\ \mathrm{X} & \mathrm{X} \\ \mathrm{X} & \mathrm{X} \\ \mathrm{X} & \mathrm{X}\end{array}$

$\mathrm{X}^{c, d}$

$\mathrm{X}^{c, d}$

$\mathrm{X} \quad \mathrm{X}$

$\mathrm{X} \quad \mathrm{X}$

$\mathrm{X} \quad \mathrm{X}$

$\mathrm{X}$

$\mathrm{X} \quad \mathrm{X}$

$\mathrm{X} \quad \mathrm{X}$

$\mathrm{X} \quad \mathrm{X}$

$\mathrm{X} \quad \mathrm{X}$

$\mathrm{X}^{c, d}$

$\mathrm{X}^{c, d}$

$\mathrm{X}$

$\mathrm{X} \quad \mathrm{X}$

$\mathrm{X} \quad \mathrm{X}$

$\mathrm{X} \quad \mathrm{X}$

$\mathrm{X} \quad \mathrm{X}$

$\mathrm{X} \quad \mathrm{X}$

$\mathrm{X} \quad \mathrm{X}$

$X \quad X$

$\mathrm{X} \quad \mathrm{X}$

$\mathrm{X} \quad \mathrm{X}$

$\mathrm{X}$

$\mathrm{X} \quad \mathrm{X}$

$\mathrm{X} \quad \mathrm{X}$

$\mathrm{X}$

X $\quad X$

$\mathrm{X} \quad \mathrm{X}$

$x^{e} \quad x$

$X \quad X$

$X \quad X$

$X \quad X$

$\mathrm{X} \quad \mathrm{X}$ 
NTP STUDIES FROM WHICH DATA WERE USED (Table 1, continued)

CHEMICAL

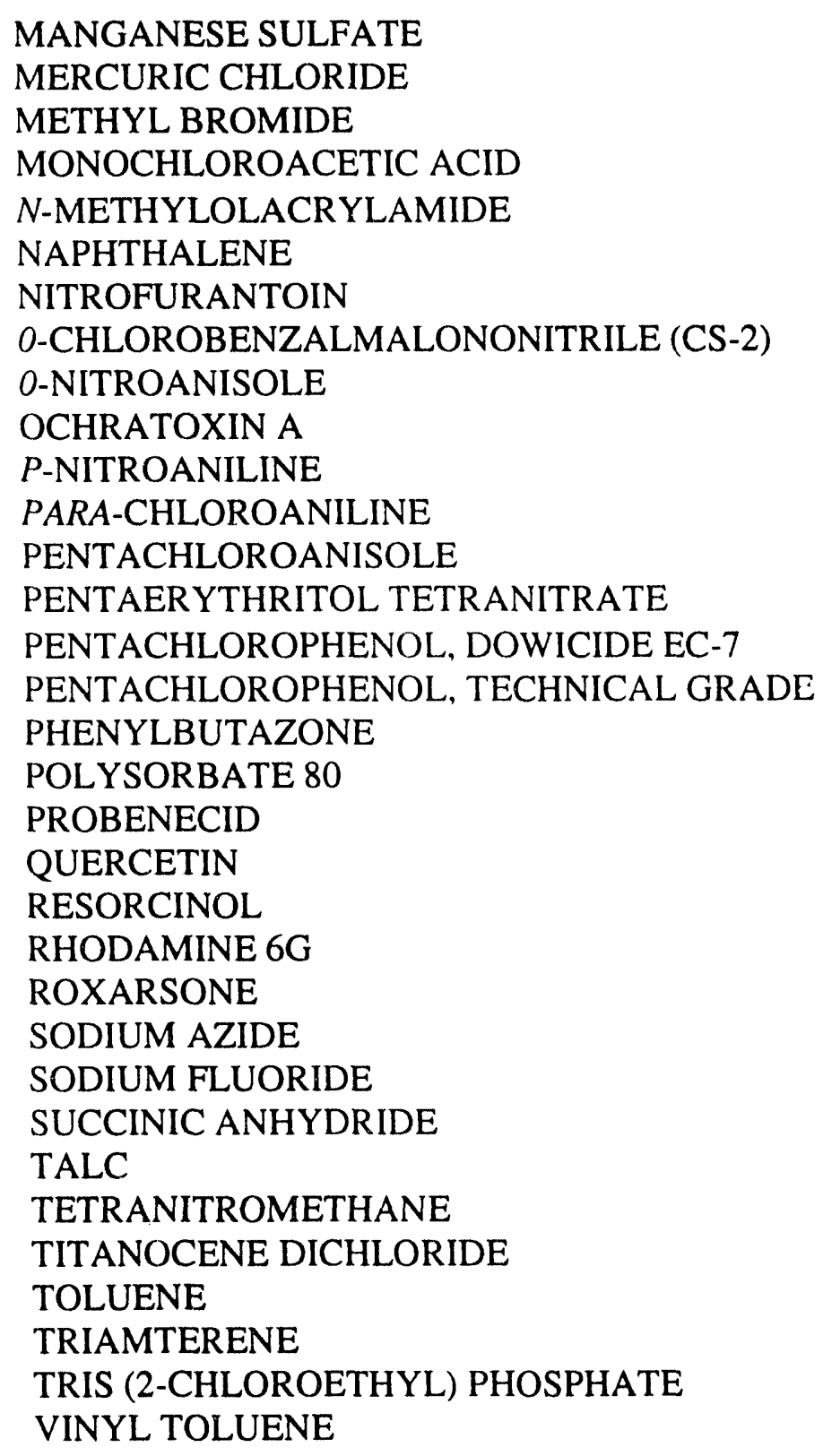

MICE

RATS

$\begin{array}{ll}\mathrm{X} & \mathrm{X} \\ \mathrm{X} & \mathrm{X} \\ \mathrm{X} & \\ \mathrm{X} & \mathrm{X} \\ \mathrm{X}^{b} & \mathrm{X} \\ \mathrm{X} & \\ \mathrm{X} & \mathrm{X} \\ \mathrm{X} & \\ \mathrm{X} & \mathrm{X} \\ & \mathrm{X}\end{array}$

$\begin{array}{ll}\mathrm{X} & \\ \mathrm{X} & \mathrm{X} \\ \mathrm{X} & \mathrm{X} \\ \mathrm{X} & \mathrm{X} \\ \mathrm{X} & \\ \mathrm{X} & \\ \mathrm{X} & \mathrm{X} \\ \mathrm{X} & \mathrm{X} \\ \mathrm{X} & \mathrm{X} \\ & \mathrm{X} \\ \mathrm{X} & \mathrm{X} \\ \mathrm{X} & \mathrm{X} \\ \mathrm{X} & \mathrm{X} \\ & \mathrm{X} \\ \mathrm{X} & \mathrm{X} \\ & \mathrm{X}\end{array}$

$\begin{array}{cc}\mathrm{X} & \mathrm{X} \\ \mathrm{X} & \mathrm{X} \\ & \mathrm{X} \\ \mathrm{X} & \mathrm{X} \\ \mathrm{X} & \mathrm{X} \\ \mathrm{X} & \mathrm{X} \\ \mathrm{X} & \end{array}$

\footnotetext{
$a_{\text {NTP studies from which treated-animal data, in addition to control animal data, were }}$ taken for use in this analysis are indicated by a superscript.

$b_{\text {Liver and Harderian-gland effects in treated animals. }}$

${ }^{C}$ Zymbal's-gland and clitoral-/preputial-gland effects in treated animals.

$d_{\text {Liver and skin effects in treated animals. }}$

$e_{\text {Liver and adrenal-gland effects in treated animals. }}$
} 


\section{Table 2}

\section{CORRELATIONS BETWEEN TUMOR PREVALENCE AT DEATH/SACRIFICE} IN CONTROL GROUPS

\section{SPECIES}

Tumor Types

RATS

Adrenal $\times$ Leukemia

Adrenal $\times$ Thyroid

Thyroid $\times$ Leukemia

Pituitary $\times$ Leukemia

Mammary $\times$ Leukemia

Mammary $\times$ Pituitary

Pituitary $\times$ Thyroid

Pituitary $\times$ Adrenal

Mammary $\times$ Adrenal

Mammary $\times$ Thyroid

\section{MICE}

Liver $\times$ Lung

Liver $\times$ Lymphoma

Lung $\times$ Lymphoma

Pituitary $\times$ Lung

Pituitary $\times$ Liver

Pituitary $\times$ Lymphoma
Sex Corr.

Females $\quad 0.060$

Males $\quad 0.025$

Females 0.041

Males $\quad-0.024$

Females -0.032

Males $\quad-0.045$

Females -0.158

Males $\quad-0.080$

Females $\quad-0.074$

Males $\quad-0.025$

Females $\quad 0.076$

Males $\quad 0.027$

Females $\quad-0.002$

Males $\quad 0.026$

Females $\quad-0.029$

Males $\quad-0.010$

Females $\quad-0.015$

Males $\quad 0.008$

Females - 0.011

Males

0.008

Females - -0.003

Males $\quad-0.022$

Females $\quad-0.029$

Males

$-0.053$

Females -0.054

Males $\quad-0.008$

Females $\quad 0.014$

Males

0.025

Females $\quad 0.020$

Males $\quad-0.074$

Females -0.041

Males $\quad 0.011$ n p-value

Adjusted

p-value

$\begin{array}{lll}2794 & 0.017 & 0.272 \\ 2786 & 0.257 & 0.982 \\ 2692 & 0.138 & 0.967 \\ 2593 & 0.342 & 0.982 \\ 2942 & 0.120 & 0.960 \\ 2827 & 0.076 & 0.783 \\ 3057 & 1.010^{-9} & 2.010^{-8} \\ 2990 & 0.000074 & 0.0013 \\ 3088 & 0.00018 & 0.00306 \\ 3045 & 0.356 & 0.982 \\ 3057 & 0.00011 & 0.0019 \\ 2990 & 0.301 & 0.982 \\ 2916 & 0.982 & 0.982 \\ 2784 & 0.254 & 0.982 \\ 2770 & 0.268 & 0.982 \\ 2739 & 0.659 & 0.982 \\ 2794 & 0.597 & 0.982 \\ 2786 & 0.835 & 0.982 \\ 2942 & 0.642 & 0.982 \\ 2827 & 0.846 & 0.982\end{array}$

$\begin{array}{lll}3058 & 0.978 & 0.978 \\ 3011 & 0.322 & 0.978 \\ 3059 & 0.185 & 0.978 \\ 3014 & 0.017 & 0.187 \\ 3071 & 0.018 & 0.198 \\ 3016 & 0.791 & 0.978 \\ 2898 & 0.592 & 0.978 \\ 2725 & 0.879 & 0.978 \\ 2891 & 0.393 & 0.978 \\ 2724 & 0.307 & 0.978 \\ 2899 & 0.058 & 0.580 \\ 2727 & 0.806 & 0.978\end{array}$


Table 3

CORRELATIONS BETWEEN TUMOR PREVALENCE AT DEATH/SACRIFICE IN CHEMICALLY AFFECTED TREATMENT GROUPS

SPECIES

Tumor Types

RATS

Liver $\times$ Zymbal's Gland

Zymbal's Gland $x$

Clitoral/Preputial Gland

Skin $\times$ Zymbal's Gland

Liver $\times$ Skin

Liver $x$

Clitoral/Preputial Gland

Skin $x$

Clitora/Preputial Gland

MICE

Liver $\times$ Adrenal Gland

Liver $\times$ Harderian Gland
Sex Corr.

Females $\quad 0.005$

Males $\quad 0.004$

Females -0.117

Males $\quad-0.152$

Females -0.065

Males $\quad-0.071$

Females 0.041

Males

0.172

Females $\quad 0.034$

Males $\quad-0.078$

Females $\quad 0.023$

Males $\quad 0.027$

Females $\quad 0.153$

Males

0.257

Females $\quad 0.236$

Males

0.024 n p-value

Adjusted

p-value

$\begin{array}{lll}498 & 0.927 & 0.961 \\ 499 & 0.961 & 0.961 \\ 590 & 0.012 & 0.12 \\ 577 & 0.003 & 0.033 \\ 500 & 0.272 & 0.961 \\ 500 & 0.213 & 0.961 \\ 498 & 0.630 & 0.961 \\ 498 & 0.002 & 0.022 \\ 488 & 0.658 & 0.961 \\ 487 & 0.187 & 0.961 \\ 489 & 0.762 & 0.961 \\ 487 & 0.735 & 0.961\end{array}$

$194 \quad 0.245$

0.49

$196 \quad 0.076$

0.228

0.016

$\begin{array}{lll}191 & 0.889 & 0.889\end{array}$ 

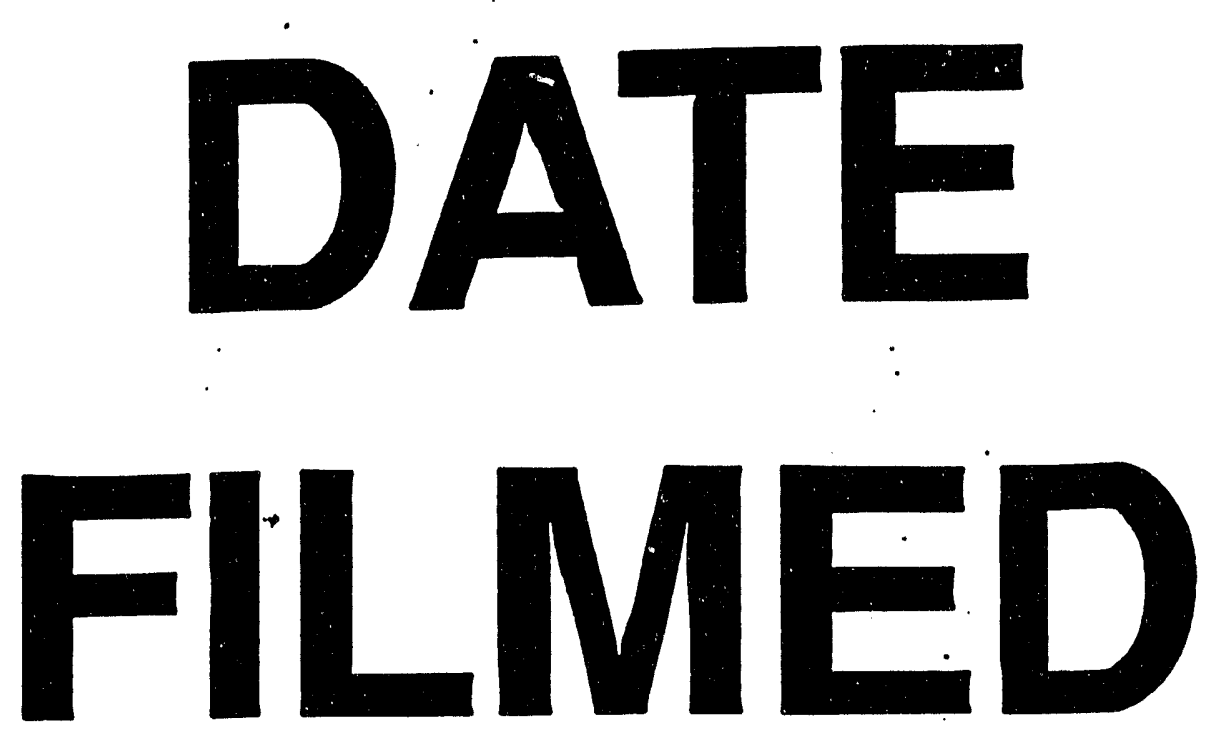

$4 / 21 / 94$
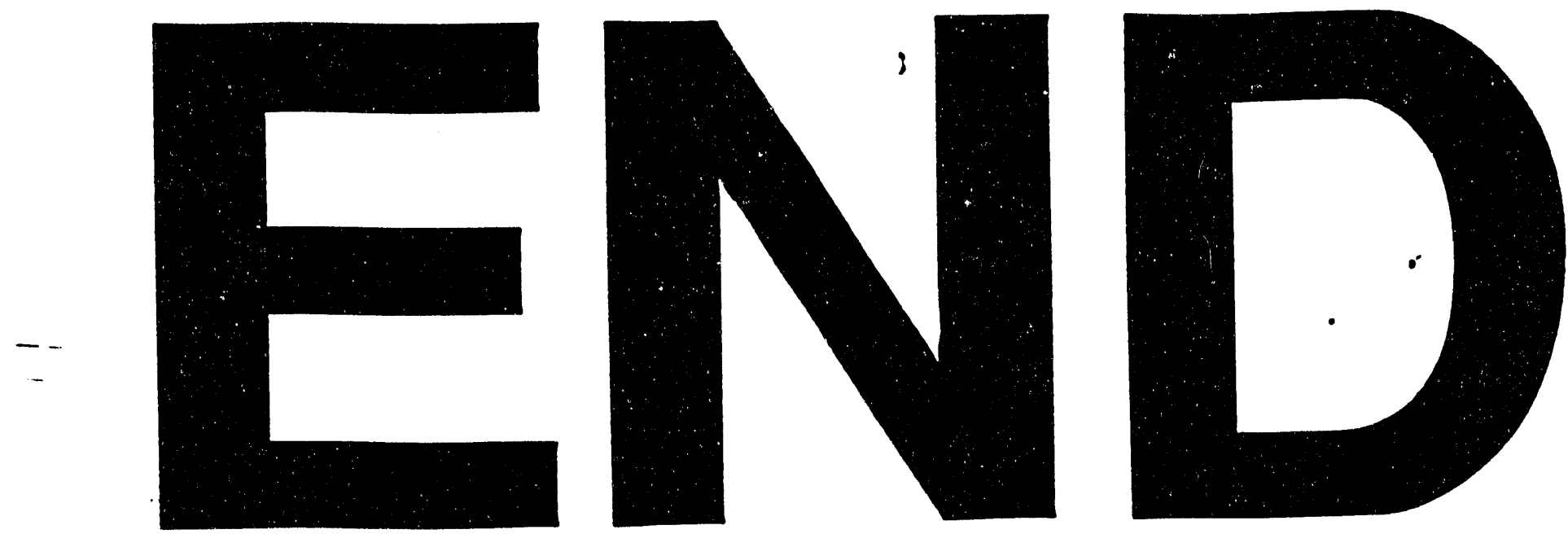
